\title{
Astroglial-Derived Periostin Promotes Axonal Regeneration after Spinal Cord Injury
}

\author{
Chung-Hsuan Shih, ${ }^{1,2,3}$ Michelle Lacagnina, ${ }^{1,2}$ Kelly Leuer-Bisciotti, ${ }^{2}$ and Christoph Pröschel ${ }^{1,2}$ \\ ${ }^{1}$ Stem Cell and Regenerative Medicine Institute, ${ }^{2}$ Department of Biomedical Genetics, and ${ }^{3}$ Department of Pathology, University of Rochester Medical \\ Center, Rochester, New York 14642
}

Traumatic spinal cord injury (SCI) results in a cascade of tissue responses leading to cell death, axonal degeneration, and glial scar formation, exacerbating the already hostile environment and further inhibiting axon regeneration. Overcoming these inhibitory cues and promoting axonal regeneration is one of the primary targets in developing a cure for SCI. Previously, we demonstrated that transplantation of bone morphogenetic protein (BMP)-induced astrocytes derived from embryonic glial-restricted precursors (GDAs ${ }^{\text {BMP }}$ ) promotes extensive axonal growth and motor function recovery in a rodent spinal cord injury model. Here, we identify periostin (POSTN), a secreted protein, as a key component of GDA ${ }^{\mathrm{BMP}}$-induced axonal regeneration. POSTN is highly expressed by GDAs ${ }^{\mathrm{BMP}}$ and the perturbation of POSTN expression by shRNA diminished GDA ${ }^{\text {BMP }}$-induced neurite extension in vitro. We also found that recombinant POSTN is sufficient to overcome the inhibitory effect of scar-associated molecules and promote neurite extension in vitro by signaling through focal adhesion kinase and Akt. Furthermore, transplantation of POSTN-deficient GDAs ${ }^{\text {BMP }}$ into the injured rat spinal cord resulted in compromised axonal regeneration, indicating that POSTN plays an essential role in GDA ${ }^{\mathrm{BMP}}$-mediated axonal regeneration. This finding reveals not only one of the major mechanisms underlying GDA ${ }^{\mathrm{BMP}}$-dependent recovery from SCI, but also the potential of POSTN as a therapeutic agent for traumatic injury of the CNS.

Key words: astrocyte; cell therapy; glial precursor; neurite outgrowth; spinal cord; support cell

\section{Introduction}

Traumatic spinal cord injury (SCI) results in both acute axonal degeneration and the generation of a glial scar that further inhibits axonal regeneration (Jones et al., 2003; Silver and Miller, 2004). Promoting axonal regeneration through such an inhibitory environment is therefore a critical component of developing more effective approaches to the treatment of SCI.

We demonstrated previously that transplantation of a specific class of astrocytes promotes extensive axonal growth and motor function recovery in a rodent SCI model (Davies et al., 2006, 2008; Davies et al., 2011). This astrocyte-based therapy relies on the use of a specific astrocyte population that is generated in vitro by directed differentiation of embryonic, glial-restricted precursor (GRP) cells (Rao et al., 1998; Mayer-Pröschel, 1999; Gregori et al., 2002). Upon treatment with either bone morphogenetic protein (BMP) or ciliary neurotrophic factor (CNTF), glial-restricted precursor cells give rise to distinct

\footnotetext{
Received July 10, 2013; revised Dec. 16, 2013; accepted Dec. 30, 2013.

Author contributions: C.-H.S. and C.P. designed research; C.-H.S., M.L., K.L.-B., and C.P. performed research; C.-H.S. and C.P. analyzed data; C.-H.S. and C.P. wrote the paper.

This work was funded by New York State (Grant C026877), Friends of Nancy Lieberman Fund, and New York State Stem Cell Science (training grant to C.-H. S.). The funders had no role in study design, data collection and analysis, decision to publish, or preparation of the manuscript. We thank M. Noble and M. Mayer-Pröschel for helpful discussions and comments.

The authors declare no competing financial interests.

Correspondence should be addressed to Chris Pröschel, Department of Biomedical Genetics, University of Rochester, Box 633, 601 Elmwood Ave., Rochester, NY 14642. E-mail: chris_proschel@urmc.rochester.edu.

DOI:10.1523/JNEUROSCI.2947-13.2014

Copyright $\odot 2014$ the authors $\quad 0270-6474 / 14 / 342438-06 \$ 15.00 / 0$
}

types of astrocyte, referred to as glial-precursor-derived astrocyte BMPs (GDAs ${ }^{\mathrm{BMP}}$ ) or GDAs ${ }^{\mathrm{CNTF}}$, respectively. However, only transplantation of GDAs ${ }^{\text {BMP }}$, not of GDAs ${ }^{\text {CNTF }}$ or GRP cells, promotes extensive neuronal survival, axonal regeneration, and functional recovery in a rodent SCI model (Davies et al., 2006, 2008; Davies et al., 2011).

The ability of GDAs ${ }^{\text {BMP }}$ to act as a multifunctional therapeutic agent is of great interest for the development of new SCI treatments and raises the question of what the possible mechanism(s) of action may be. The improved outcome of multiple injury-related processes, including a reduction in glial scars, improved neuronal survival, and axonal outgrowth, suggest that GDAs ${ }^{\mathrm{BMP}}$ target several pathways at once.

Microarray analysis of $\mathrm{GDA}^{\mathrm{BMP}}$-expressed proteins led to the identification of the extracellular matrix protein periostin (POSTN) as a novel factor not previously known to play a role in SCI repair. POSTN was highly and selectively expressed in GDAs ${ }^{\text {BMP }}$ and disruption of POSTN expression in GDAs ${ }^{\text {BMP }}$ compromised the ability of GDAs ${ }^{\text {BMP }}$ to support axon regeneration in a rat model of SCI. In addition, recombinant POSTN promoted neurite outgrowth in vitro, even in the presence of neurite outgrowth inhibitory substrates, suggesting that POSTN may mediate an important part of the ability of GDAs ${ }^{\text {BMP }}$ to remodel the injury environment.

\section{Materials and Methods}

Antibodies. The antibodies used were as follows: anti-focal adhesion kinase (anti-FAK), anti-phospho-FAK(Y-397), anti-Akt, anti-phosphoAkt(S-473), and anti- $\beta$-actin (Santa Cruz Biotechnology) and anti- 

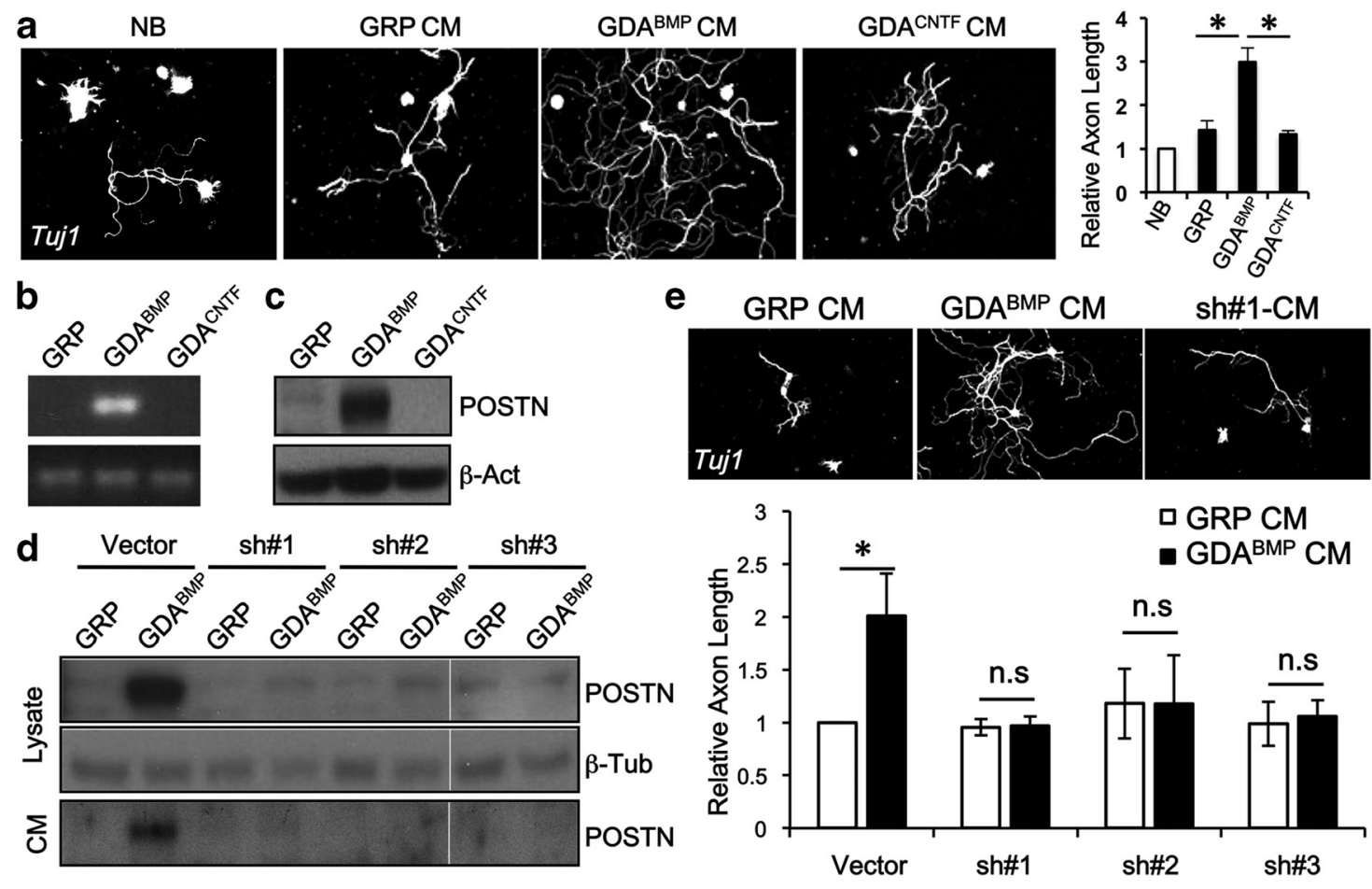

Figure 1. POSTN mediates GDA ${ }^{\text {BMP }}$-induced neurite extension in vitro. $\boldsymbol{a}$, Adult DRGNs were cultured in conditioned medium (CM) from GRPs, GDAs ${ }^{\text {BMP }}$, or GDAs ${ }^{\text {CNTF. }}$. After $3 \mathrm{~d}$, DRGNs were immunostained with Tujl antibody. Scale bar, $100 \mu \mathrm{m}$. Relative axon length of DRGNs grown in neurobasal medium (NB), CM from GRPs, GDAs ${ }^{\text {BMP }}$, or GDAs ${ }^{\text {CNTF. }}$. $(n=3)$. Data are mean \pm SD. ${ }^{*} p<$ $0.05, t$ test. Expression level of POSTN in GRP, GDAs ${ }^{\text {BMP }}$, and GDAs ${ }^{\text {CNTF }}$ measured by semiquantitative PCR $(\boldsymbol{b})$ or Western blot analysis $(\boldsymbol{c})$. $\boldsymbol{d}$, GRP cells stably transduced with vector or three different POSTN-specific shRNA expression constructs. GRPs were either maintained as precursors or differentiated into GDAs ${ }^{\text {BMP }}$. POSTN was detected in CM and lysates by Western blot. $\boldsymbol{e}$, DRGNs cultured for $3 \mathrm{~d}$ in CM collected from GRPs or GDAs ${ }^{\text {BMP }}$ infected with either control or POSTN shRNA constructs. Upper panels show representative images of cultured DRGs. Lower panel presents quantification of relative neurite lengths. Neurites labelled by Tujl immunostaining. Scale bar, $100 \mu \mathrm{m}$. Quantitative result of $\boldsymbol{e}(n=3)$. Data are mean \pm SD. ${ }^{*} p<0.05, t$ test.

POSTN and anti-HO1 (Abcam). POSTN specific primers used in semiquantitative RT-PCR were as follows: 5'-GTGGCAGCAC CTTCAAAGAAAT-3' and 5'-CTTCTGTCACTGTTTCACCTTCTTT AA-3'.

Isolation of GRPs, generation of GDAs and POSTN knock-down $G D A s^{B M P}$. GRPs were isolated as described previously (Davies et al., 2006). Dissociated cells from day 13.5 spinal cords of transgenic F344 rat embryos expressing human placental alkaline phosphatase were sorted using magnetic bead-conjugated PSA-NCAM and A2B5 antibody (Miltenyi Biotec). GRPs were cultured on fibronectin/laminin-coated dishes and maintained in DMEM-F12 medium (Invitrogen) with 10 $\mathrm{ng} / \mathrm{ml}$ basic fibroblast growth factor (bFGF; Miltenyi Biotec) with N2 supplement (Invitrogen). To differentiate GDAs ${ }^{\text {BMP }}$ from GDAs ${ }^{\text {CNTF }}$, GRPs were exposed to $1 \mathrm{ng} / \mathrm{ml} \mathrm{bFGF}$ and $10 \mathrm{ng} / \mathrm{ml} \mathrm{BMP} 4$ (R\&D Systems) or $10 \mathrm{ng} / \mathrm{ml}$ CNTF (Peprotech), respectively, for $6 \mathrm{~d}$. For POSTN knockdown, GRPs stably transduced with lentiviral control vector or POSTN specific short hairpin RNA constructs were induced with BMP-4. Target sequences were as follows: sh\#1: GCAGAGGACTAGAGAACAATG; Sh\#2: GCGCCTTCTTAAGCTAATTCT; sh\#3: GCAGAAGATGAGC TTTCATCA.

Isolation of neurons. Dorsal root ganglions dissected from adult Sprague Dawley rats were sequentially digested with collagenase II (Worthington)/dispase II (Roche), and papain (Worthington). Cell suspensions were applied to a $0.5 \mathrm{M}$ sucrose cushion and at centrifuged $800 \times g$ for $10 \mathrm{~min}$. Cells were plated in neurobasal/B27 medium (Invitrogen). Cerebellar granule neurons (CGNs) were isolated from cerebellum dissected from day 7 Sprague Dawley rats that was digested with papain and DNase, cell debris was removed by sucrose gradient centrifugation, pellets were further purified with a Percoll (Sigma) gradient, and CGNs were plated in neurobasal/B27 medium.

In vitro neurite outgrowth assay. GRPs were seeded and either maintained as progenitors or differentiated into GDAs. After $6 \mathrm{~d}$, the culture media was changed to neural basal/B27. After $24 \mathrm{~h}$, GRP- or GDA- conditioned media were collected. Size fractionation of conditioned media was performed using a Centricon centrifugal filter (Millipore). Dorsal root ganglion neurons (DRGNs) were seeded on poly-L-lysine-coated plates and GRP- or GDA-conditioned media were added immediately thereafter. After $72 \mathrm{~h}$, DRGNs were fixed and stained with TujI antibody (Sigma). Neurite length was measured using either ImageJ to quantify the absolute neurite length or Celigo adherent cytometer to quantify the confluence of TujI-stained neurites, providing a quantitative measurement of neurite outgrowth. To test the effect of recombinant POSTN on neurite extension and cell signaling, CGNs were seeded at the density of $50,000 \mathrm{cells} / \mathrm{cm}^{2}$ on plates precoated with fibronectin (Millipore) with or without $\mathrm{rPOSTN}(10 \mu \mathrm{g} / \mathrm{ml}$; R\&D Systems). The FAK inhibitors PF $573228(10 \mu \mathrm{M}$; Tocris Bioscience) and FAK inhibitor $14(3 \mu \mathrm{M}$; Tocris Bioscience) and the Akt inhibitors Akt1/2 inhibitor (10 $\mu \mathrm{M}$; Sigma) and SH-6 (10 $\mu \mathrm{M}$; Calbiochem) were added immediately. After 24 h, CGNs were fixed and stained with TujI antibody or harvested for Western blot. To test the effect of rPOSTN on substrates inhibitory for axon growth, DRGNs and CGNs were seeded on plates precoated with $1 \mu \mathrm{g} / \mathrm{ml} \mathrm{laminin}$ and combinations of $\operatorname{rPOSTN}(1,2.5$, or $5 \mu \mathrm{g} / \mathrm{ml})$, chondroitin sulfate proteoglycan (CSPG) extracts $(2.5 \mu \mathrm{g} / \mathrm{ml}$; Millipore $)$ or myelin extract (Larocca and Norton, 2007) as indicated.

Spinal cord lesion model. Adult female Sprague Dawley rats (Jackson Laboratory) were anesthetized using ketamine $(80 \mathrm{mg} / \mathrm{kg})$ and xylazine ( $4 \mathrm{mg} / \mathrm{kg}$ ). The right dorsal column was transected between cervical level 1 and 2 using a microscissor. A total of $8 \mu \mathrm{l}$ of PBS or GDA suspension $(50,000$ cells $/ \mu \mathrm{l})$ were acutely injected into 4 different sites adjacent to the lesion ( 2 injections each, rostral/caudal to the lesion). To trace the endogenous axons, $100 \mathrm{ng}$ of biotin dextran amine 10,000 MW (Invitrogen) was injected into the right dorsal column at the $\mathrm{C} 3 / 4$ level. Animals were perfused $7 \mathrm{~d}$ after injury. For histological analysis, serial sagittal sections were stained. The lesion center was identified by staining of infiltrating microphages with ED1 antibody (Abcam). BDA labeling was 
a
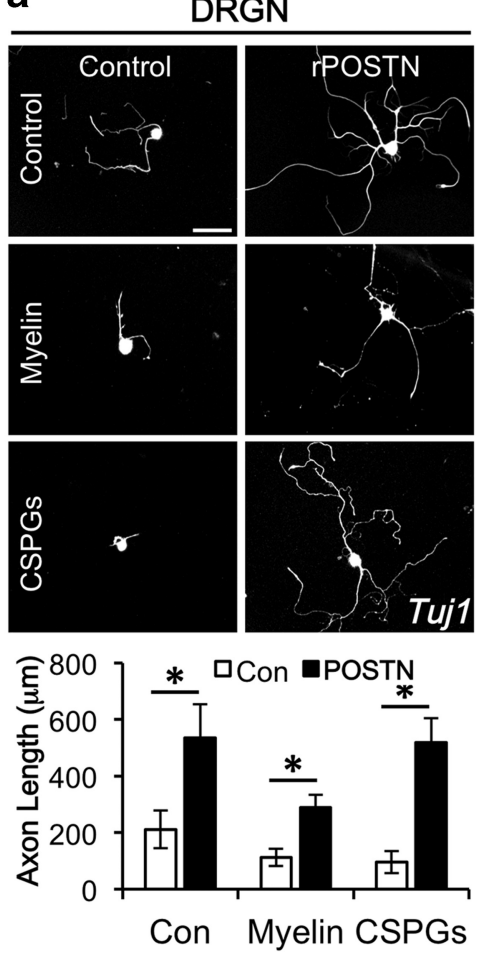

b

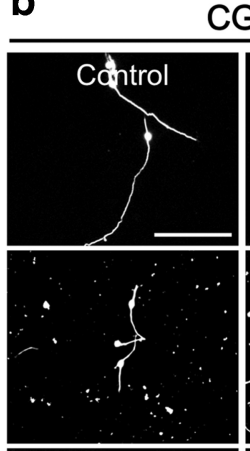

CGN
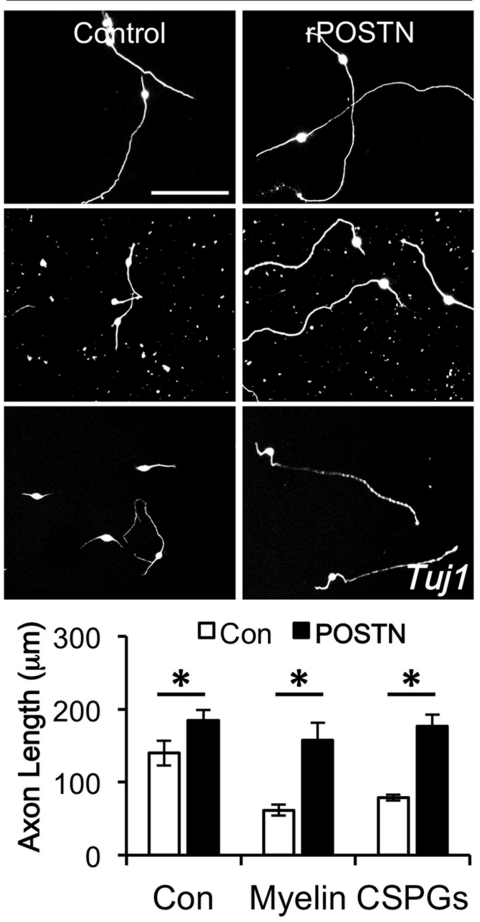

C
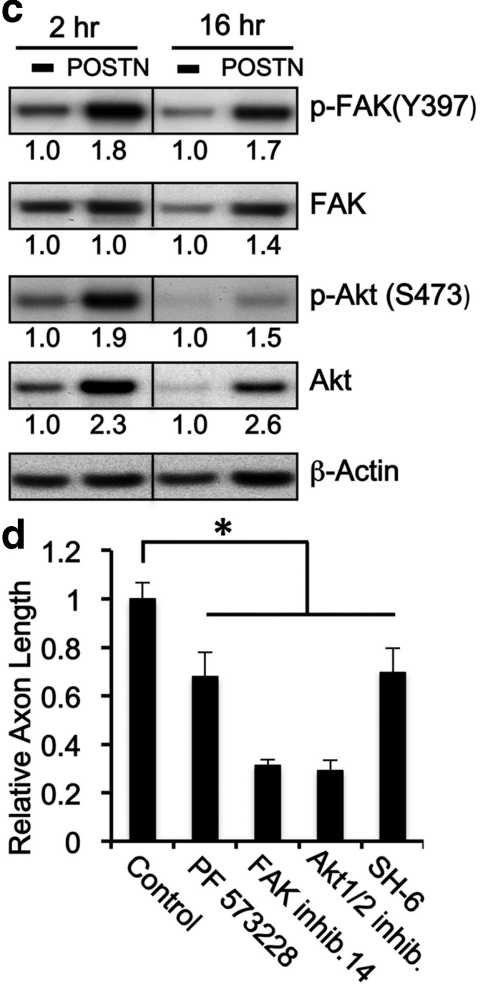

Figure 2. Recombinant POSTN overcomes inhibitory effect of myelin and chondroitin sulfate proteoglycans and promotes neurite outgrowth in vitro through FAK and Akt signaling pathway. $\boldsymbol{a}$, $\boldsymbol{b}$, Adult DRGNs $(\boldsymbol{a})$ and P7 CGNs $(\boldsymbol{b})$ cultured with or without myelin/CSPGs in the presence or absence of recombinant POSTN. Cells were immunostained with Tujl antibody. Scale bars, $100 \mu \mathrm{m}$. Mean neurite length is shown in $\boldsymbol{e}(n=3)$. Data are mean \pm SD. ${ }^{*} p<0.05, t$ test. $c$, G Gs treated with control vehicle or recombinant POSTN $4 \mathrm{~h}$ after plating. Cell lysates were harvested 2 and $16 \mathrm{~h}$ after treatment for Western blot analysis. Relative expression levels were normalized to b-actin and then untreated samples at $2 \mathrm{~h}$. $\boldsymbol{d}$, CGNs were seeded with or without recombinant POSTN and treated with control vehicle or FAK/Akt inhibitors. Relative axon length $24 \mathrm{~h}$ after plating is shown $(n=3)$. Data are mean \pm SD. ${ }^{*} p<0.05$, ANOVA.

visualized using tyramide amplification (Invitrogen) and quantified using ImageJ.

\section{Results}

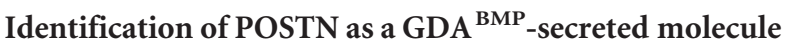
We showed previously that transplantation of GDAs ${ }^{\text {BMP }}$ promotes axonal regeneration in a rodent transection SCI model (Davies et al., 2006, 2008; Davies et al., 2011). When we cultured adult DRGNs, which project sensory axons into spinal cord, using conditioned media from GRPs, GDAs ${ }^{\text {BMP }}$, and GDAs ${ }^{\text {CNTF }}$, we found that GDA ${ }^{\text {BMP }}$ conditioned media was sufficient to promote extensive neurite outgrowth of DRGNs (Fig. 1a). Although conditioned medium from GRPs and GDAs ${ }^{\text {CNTF }}$ did not have a significant effect on neurite outgrowth $\left(<1.5\right.$-fold), GDA ${ }^{\text {BMP }}$ conditioned medium increased neurite outgrowth 3-fold (Fig. $1 b$ ). Size fractionation of CM placed the majority of neurite outgrowth-promoting activity of $\mathrm{GDA}^{\mathrm{BMP}}$ conditioned medium in the $\geq 100 \mathrm{kDa}$ fraction. Microarray analysis of genes differentially expressed in GRPs, GDAs ${ }^{\text {BMP }}$, and GDAs ${ }^{\text {CNTF }}$ identified POSTN as a secreted protein of $\sim 100 \mathrm{kDa}$ specifically expressed in GDAs ${ }^{\text {BMP }}$. Selective expression of POSTN by GDAs ${ }^{\text {BMP }}$ was further validated by semiquantitative PCR and Western blot analysis (Fig. 1b,c), demonstrating specific expression of an $\sim 98$ $\mathrm{kDa}$ periostin protein in GDAs ${ }^{\mathrm{BMP}}$.

To test the contribution of POSTN to GDA ${ }^{\mathrm{BMP}}$ neurite outgrowth-promoting function, we disrupted expression of POSTN in GDAs ${ }^{\text {BMP }}$. GRP cells stably transduced with either POSTN-specific shRNA constructs or control vector were either maintained as precursors or differentiated into GDAs ${ }^{\text {BMP }}$. Western blot analysis showed that expression of POSTN in these
GDAs ${ }^{\text {BMP }}$ was significantly decreased in both cell lysate and conditioned media by three distinct POSTN-targeting shRNA constructs (Fig. 1d). We further found that the neurite extensionpromoting activity in GDA ${ }^{\text {BMP }}$ conditioned media was reduced to control levels when POSTN expression was disrupted (Fig. 1e).

\section{Recombinant POSTN promotes neurite extension in the} presence of axonal growth inhibitors

To determine whether POSTN protein is sufficient to increase neurite outgrowth, we tested the effect of recombinant POSTN (rPOSTN) and found it to be sufficient to enhance neurite outgrowth in both DRGNs and P7 CGNs (Fig. 2a,b). Because we had previously observed the ability of GDA ${ }^{\mathrm{BMP}}$ transplants to promote neurite outgrowth in an SCI environment, we tested the effect of rPOSTN in the presence of injury-associated molecules that are known to be inhibitory to axonal growth (Giger et al., 2008). Adult rat DRGNs or CGNs were grown on the inhibitory substrates of rat spinal cord myelin extract or CSPGs in the presence or absence of rPOSTN. In the absence of POSTN, both inhibitory substrates reduced neurite length to $\sim 50 \%$ of control values. In contrast, the addition of recombinant POSTN restored neurite length to near control values in DRGNs growing on CSPGs and significantly enhanced neurite outgrowth from DRGNs growing on myelin extract (Fig. 2a). Similarly, POSTN increased levels of neurite outgrowth of CGNs almost to control values on both myelin extract- and CPSG-treated substrates (Fig. $2 b)$. Reduction of rPOSTN from 5 to 2.5 or $1 \mu \mathrm{g} / \mathrm{ml}$ in the presence of CSPGs did not significantly limit the neurite outgrowthpromoting activity of rPOSTN in DRGNs $(520 \pm 85,486 \pm 63$, 
a

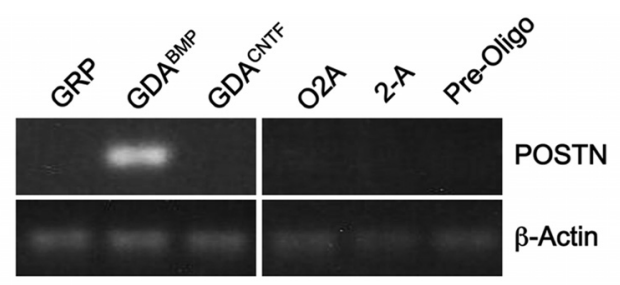

b

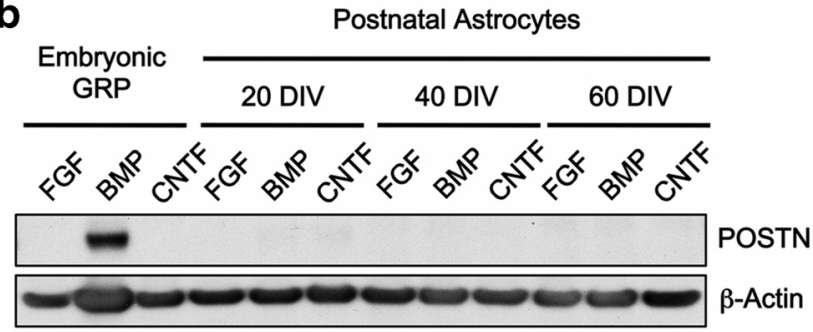

c

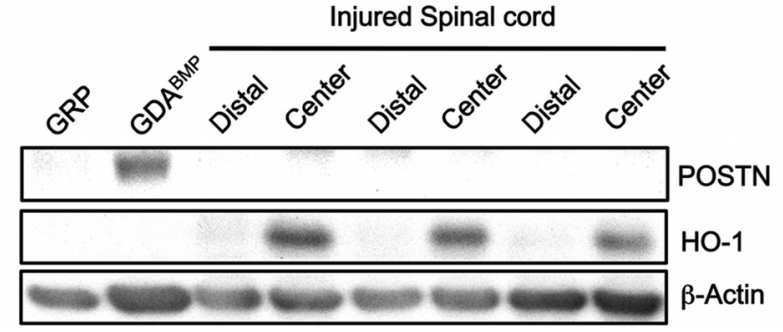

Figure 3. POSTN is highly expressed in GDA ${ }^{B M P}$, but not in postnatal astrocytes or adult spinal cord. $\boldsymbol{a}$, GRPs or postnatal 02As were either maintained as precursors or differentiated into $G D A s^{B M P}, G D A s{ }^{C N T F}$, type 2 astrocytes (2-A), or preoligodendrocytes by exposing to BMP or CNTF, respectively. Expression level of POSTN was measured by semiquantitative PCR. $\boldsymbol{b}$, Embryonic GRPs and postnatal astrocytes cultured in vitro for 20,40, or $60 \mathrm{~d}$ were treated with FGF, BMP, or CNTF for $6 \mathrm{~d}$. Expression of POSTN was measured by Western blot analysis. c, Expression level of POSTN in GRPs, GDAs ${ }^{\text {BMP }}$, intact (distal) or injured (center) adult spinal cord tissues measured by Western blot analysis. Expression of the inflammatory protein H0-1 maps the injury.

and $390 \pm 91 \mu \mathrm{m}$, respectively; mean $\pm \mathrm{SD}, n=3, p>0.05$, $t$ test vs $123 \pm 35 \mu \mathrm{m}$ ) without the addition of rPOSTN.

\section{FAK and Akt are downstream effectors of POSTN-induced axonal growth}

POSTN exerts its biological functions, including promoting cell proliferation, adhesion, migration, and tissue regeneration, in cardiac and vascular smooth muscle cells through interaction with integrins and their downstream mediators, FAK and Akt (Gillan et al., 2002; Li et al., 2010). Activation of these pathways promotes axonal extension in several types of neurons (Robles and Gomez, 2006; Tucker et al., 2008). We therefore next investigated whether these pathways were important in mediating POSTN's effects on CNS neurons. In these experiments, CGNs were seeded on fibronectin-coated dishes for $4 \mathrm{~h}$ to allow attachment, after which recombinant POSTN or control vehicle was added to medium. Cell lysates were harvested after 2 or $16 \mathrm{~h}$ and immunoblotted for phospho-FAK, FAK, phospho-Akt, Akt, and $\beta$-actin. POSTN significantly increased FAK phosphorylation by 1.8 -fold at $2 \mathrm{~h}$ and by 1.7 -fold after $16 \mathrm{~h}$ of treatment and increased total FAK levels by 1.4 -fold at $16 \mathrm{~h}$. POSTN also increased both phosphorylated and total Akt at both 2 and $16 \mathrm{~h}$ over untreated cells. POSTN-induced neurite outgrowth in CGNs was also reduced to $30-70 \%$ in the presence of FAK or Akt inhibitors (Fig. 2d).
Periostin is highly expressed in GDAs ${ }^{\text {BMP }}$, but not in postnatal astrocytes or injured spinal cord

To determine whether POSTN is selectively expressed by GDAs ${ }^{\text {BMP }}$ among other types of glial cells, we compared expression in GRPs, postnatal oligodendrocyte-type 2 astrocyte (O-2A) progenitors, and postnatal astrocytes. Our data indicated that POSTN is not expressed in O2A progenitors, O2A-derived oligodendrocytes, or O2A-derived astrocytes induced by BMP treatment (Fig. 3a). POSTN expression was then assessed in postnatal astrocytes that were cultured in vitro for 20,40 , or $60 \mathrm{~d}$ as a surrogate of adult astrocytes. Similarly, we did not find evidence of POSTN expression in these astrocytes, even after BMP treatment (Fig. 3b). Unlike in cardiac tissue after infarction or brain tissue after stroke (Oka et al., 2007; Shimamura et al., 2012), reexpression of POSTN does not occur in injured spinal cord. We compared POSTN expression in the intact (distal) or injured (center, indicated by inflammatory protein HO-1) adult spinal cord tissues and did not detect POSTN in either intact or injured CNS tissues (Fig. 3c), suggesting that exogenous POSTN provided by transplanted GDAs ${ }^{\mathrm{BMP}}$ may contribute to promotion of axonal regeneration.

\section{Periostin mediates $\mathrm{GDA}^{\mathrm{BMP}}$-dependent axonal regeneration after SCI}

To determine the contribution of POSTN to GDA ${ }^{\mathrm{BMP}}$-induced axonal regeneration in vivo, we transplanted POSTN knockdown GDAs ${ }^{\text {BMP }}$ (GDAs ${ }^{\text {BMP }}$-POSTNsh) into a rat model of hemisection SCI. Injuries were placed on the right side of the dorsal column at the $\mathrm{C} 1 / 2$ level. Saline or GDAs ${ }^{\mathrm{BMP}}$ infected with either control vector or POSTN-specific shRNA were injected perilesionally. We evaluated axonal regeneration by tracing biotinylated dextran amine (BDA)-labeled ascending sensory axons. The lesion center was identified by immunostaining of infiltrating ED- $1^{+}$macrophages. Histological analysis of macrophage and glial scar markers indicated that the lesion extended $1 \mathrm{~mm}$ rostral to caudal and $0.8 \mathrm{~mm}$ deep dorsal to ventral (data not shown) and included dorsal white matter tracts and partial gray matter tracts, as illustrated. Identifying transplanted cells by human placental alkaline phosphatase immunostaining indicated substantial $\mathrm{GDA}^{\mathrm{BMP}}$ survival and migration to the lesion center $7 \mathrm{~d}$ after transplantation (data not shown). Transplantation experiments revealed that POSTN expression was critical in $\mathrm{GDA}^{\mathrm{BMP}}$ mediated neurite outgrowth in vivo. Animals in all groups showed a similar degree of injury, as determined by ED1 labeling (Fig. 4a). GDA ${ }^{\mathrm{BMP}}$-Vec-transplanted animals showed significant axonal growth into the lesion center, as predicted from our previous studies. In contrast, transplantation of POSTN-deficient GDAs ${ }^{\text {BMP }}$ did not promote axonal growth into the lesion and were not different from saline-treated animals (Fig. 4d). Quantification of axonal regeneration further emphasized the importance of POSTN expression in GDA ${ }^{\mathrm{BMP}}$ function. Axonal regeneration was measured by quantifying the percentage of BDA-labeled axons that extended into the lesion site. GDA ${ }^{\mathrm{BMP}}$-Vec-transplanted animals showed $>80 \%$ and $>50 \%$ of labeled axons at the lesion center and $400 \mu \mathrm{m}$ rostral to the lesion center, respectively. In $\mathrm{GDA}^{\mathrm{BMP}}$-POSTNsh-transplanted and in the saline-treated group, only $50 \%$ of labeled axons grew to the lesion center and only $15 \%$ grew $400 \mu \mathrm{m}$ rostral to the lesion center.

\section{Discussion}

We have discovered that POSTN plays a critical role in GDA ${ }^{\text {BMP }}$ mediated promotion of axonal regeneration in the injured spinal cord. Although our previous studies demonstrated the increased expression of the neurotrophic factors BDNF and GDNF in 
GDAs $^{\text {BMP }}$ over GDAs ${ }^{\text {CNTF }}$ or parental GRP cells (Davies et al., 2011), POSTN is the first agent identified that plays a critical role in the regeneration-promoting functions of these astrocytes., Our experiments provide a novel function of POSTN in promoting neurite extension and axonal regeneration after SCI.

POSTN is transiently expressed in multiple tissues, including the CNS, during early development. In the mouse CNS, POSTN expression spans from embryonic days 12.5-19.5 (Zhu et al., 2008), a period that coincides with a critical period for neuron maturation and axon extension. Increased expression of POSTN after injury has been found in several adult tissues, such as fractured-bone-infarcted myocardial tissue, and during cutaneous wound healing (Oka et al., 2007; Zhu et al., 2009; Nishiyama et al., 2011). Delivery of recombinant POSTN has also been shown to promote cardiomyocyte proliferation and to improve cardiac remodeling (Dorn, 2007; Kühn et al., 2007). These data suggest an important role for POSTN in tissue repair and regeneration. Moreover, POSTN contains four domains that share homology with the insect growth cone guidance protein fasciclin I, suggesting a role for POSTN in neurite outgrowth (Takeshita et al., 1993). Recently, POSTN has been shown to be reexpressed in the CNS after ischemic injury and to reduce infarct volume when administered via intracerebroventricular injection (Shimamura et al., 2012).

Our data indicate that POSTN acts directly on neurons to promote neurite outgrowth and we also found that these effects are dependent on the activation of FAK and Akt. These outcomes are in agreement with studies on other cells demonstrating that POSTN promotes cell survival, proliferation, adhesion, and migration in non-neural cells through interacting with integrins $\alpha 5 / \beta 1$ and $\alpha 5 / \beta 3$ and causing the downstream activation of FAK, PI3K, and Akt (Gillan et al., 2002; Bao et al., 2004; Li et al., 2010). Activation of these pathways promotes axonal extension in several types of neurons (Robles and Gomez, 2006; Tucker et al., 2008). Activation of FAK pathways may help to explain the ability of POSTN to promote neuronal growth on otherwise inhibitory substrates, such as myelin extract and CSPGs (Hu and Strittmatter, 2008; Tan et al., 2011). However, despite the ability of POSTN to activate these pathways, it was not required for attachment, survival, or growth of POSTN knock-down GRP cells and GDAs ${ }^{\text {BMP }}$ themselves because we did not find significant changes in cell attachment, survival, or growth (data not shown), raising the possibility that neurons are the primary target of POSTN activity in the CNS.

POSTN has also been found to bind several other extracellular matrix proteins, including collagen I, fibronectin, and tenascin- $\mathrm{C}$ (Kii et al., 2010). Although we did not observe a significant change in ED- $1^{+}$monocyte infiltration after transplantation of POSTN knock-down GDAs ${ }^{\text {BMP }}$, it remains to be seen whether POSTN modulates the effect of tenascin-C on lymphocyte and neutrophil infiltration and neurite sprouting (Chen et al., 2010; Schreiber et al., 2013) or if POSTN is required for axonal growth in the presence of collagen (Soderblom et al., 2013). Loss of POSTN also did not appear to alter GDA ${ }^{\text {BMP }}$-transplantinduced organization of injured tissue, which may be attributable to the effect of GDNF expressed by GDAs ${ }^{\text {BMP }}$ (Deng et al., 2011).

In addition, the ability of GDAs ${ }^{\text {BMP }}$ to also suppress scar formation and to promote survival of multiple neuronal populations suggests that POSTN expression may represent just one of several properties of these cells. POSTN is the first agent we have identified that is essential in the ability of GDAs ${ }^{\text {BMP }}$ to promote regeneration after SCI and the marked effects of POSTN knockdown suggests that this protein is of particular importance in understanding the ability of these cells to promote axon regeneration. This also raises the question of whether POSTN might be useful on its own in promoting recovery after experimental SCI.

\section{References}

Bao S, Ouyang G, Bai X, Huang Z, Ma C, Liu M, Shao R, Anderson RM, Rich JN, Wang XF (2004) Periostin potently promotes metastatic growth of colon cancer by augmenting cell survival via the Akt/PKB pathway. Cancer Cell 5:329-339. CrossRef Medline

Chen J, Joon Lee H, Jakovcevski I, Shah R, Bhagat N, Loers G, Liu HY, Meiners S, Taschenberger G, Kügler S, Irintchev A, Schachner M (2010) 
The extracellular matrix glycoprotein tenascin- $\mathrm{C}$ is beneficial for spinal cord regeneration. Mol Ther 18:1769-1777. CrossRef Medline

Davies JE, Huang C, Pröschel C, Noble M, Mayer-Pröschel M, Davies SJ (2006) Astrocytes derived from glial-restricted precursors promote spinal cord repair. J Biol 5:7. CrossRef Medline

Davies JE, Pröschel C, Zhang N, Noble M, Mayer-Pröschel M, Davies SJ (2008) Transplanted astrocytes derived from BMP- or CNTF-treated glial-restricted precursors have opposite effects on recovery and allodynia after spinal cord injury. J Biol 7:24. CrossRef Medline

Davies SJ, Shih CH, Noble M, Mayer-Pröschel M, Davies JE, Pröschel C (2011) Transplantation of specific human astrocytes promotes functional recovery after spinal cord injury. PLoS One 6:e17328. CrossRef Medline

Deng LX, Hu J, Liu N, Wang X, Smith GM, Wen X, Xu XM (2011) GDNF modifies reactive astrogliosis allowing robust axonal regeneration through Schwann cell-seeded guidance channels after spinal cord injury. Exp Neurol 229:238-250. CrossRef Medline

Dorn GW 2nd (2007) Periostin and myocardial repair, regeneration, and recovery. N Engl J Med 357:1552-1554. CrossRef Medline

Giger RJ, Venkatesh K, Chivatakarn O, Raiker SJ, Robak L, Hofer T, Lee H, Rader C (2008) Mechanisms of CNS myelin inhibition: evidence for distinct and neuronal cell type specific receptor systems. Restor Neurol Neurosci 26:97-115. Medline

Gillan L, Matei D, Fishman DA, Gerbin CS, Karlan BY, Chang DD (2002) Periostin secreted by epithelial ovarian carcinoma is a ligand for alpha(V)beta(3) and alpha(V)beta(5) integrins and promotes cell motility. Cancer Res 62:5358-5364. Medline

Gregori N, Pröschel C, Noble M, Mayer-Pröschel M (2002) The tripotential glial-restricted precursor (GRP) cell and glial development in the spinal cord: generation of bipotential oligodendrocyte-type-2 astrocyte progenitor cells and dorsal-ventral differences in GRP cell function. J Neurosci 22:248-256. Medline

Hu F, Strittmatter SM (2008) The N-terminal domain of Nogo-A inhibits cell adhesion and axonal outgrowth by an integrin-specific mechanism. J Neurosci 28:1262-1269. CrossRef Medline

Jones LL, Margolis RU, Tuszynski MH (2003) The chondroitin sulfate proteoglycans neurocan, brevican, phosphacan, and versican are differentially regulated following spinal cord injury. Exp Neurol 182:399-411. CrossRef Medline

Kii I, Nishiyama T, Li M, Matsumoto K, Saito M, Amizuka N, Kudo A (2010) Incorporation of tenascin- $\mathrm{C}$ into the extracellular matrix by periostin underlies an extracellular meshwork architecture. J Biol Chem 285:20282039. CrossRef Medline

Kühn B, del Monte F, Hajjar RJ, Chang YS, Lebeche D, Arab S, Keating MT (2007) Periostin induces proliferation of differentiated cardiomyocytes and promotes cardiac repair. Nat Med 13:962-969. CrossRef Medline

Larocca JN, Norton WT (2007) Isolation of myelin. Curr Protoc Cell Biol Chapter 3:Unit3.25. CrossRef Medline

Li G, Jin R, Norris RA, Zhang L, Yu S, Wu F, Markwald RR, Nanda A, Conway SJ, Smyth SS, Granger DN (2010) Periostin mediates vascular smooth muscle cell migration through the integrins alphanubeta 3 and alphanubeta5 and focal adhesion kinase (FAK) pathway. Atherosclerosis 208: 358-365. CrossRef Medline

Mayer-Pröschel M (1999) Cell differentiation in the embryonic mammalian spinal cord. J Neural Transm Suppl 55:1-8. Medline

Nishiyama T, Kii I, Kashima TG, Kikuchi Y, Ohazama A, Shimazaki M, Fukayama M, Kudo A (2011) Delayed re-epithelialization in periostindeficient mice during cutaneous wound healing. PLoS One 6:e18410. CrossRef Medline

Oka T, Xu J, Kaiser RA, Melendez J, Hambleton M, Sargent MA, Lorts A, Brunskill EW, Dorn GW 2nd, Conway SJ, Aronow BJ, Robbins J, Molkentin JD (2007) Genetic manipulation of periostin expression reveals a role in cardiac hypertrophy and ventricular remodeling. Circ Res 101: 313-321. CrossRef Medline

Rao MS, Noble M, Mayer-Pröschel M (1998) A tripotential glial precursor cell is present in the developing spinal cord. Proc Natl Acad Sci U S A 95:3996-4001. CrossRef Medline

Robles E, Gomez TM (2006) Focal adhesion kinase signaling at sites of integrin-mediated adhesion controls axon pathfinding. Nat Neurosci 9:1274-1283. CrossRef Medline

Schreiber J, Schachner M, Schumacher U, Lorke DE (2013) Extracellular matrix alterations, accelerated leukocyte infiltration and enhanced axonal sprouting after spinal cord hemisection in tenascin-C-deficient mice. Acta Histochem 115:865-878. CrossRef Medline

Shimamura M, Taniyama Y, Katsuragi N, Koibuchi N, Kyutoku M, Sato N, Allahtavakoli M, Wakayama K, Nakagami H, Morishita R (2012) Role of central nervous system periostin in cerebral ischemia. Stroke 43:11081114. CrossRef Medline

Silver J, Miller JH (2004) Regeneration beyond the glial scar. Nat Rev Neurosci 5:146-156. CrossRef Medline

Soderblom C, Luo X, Blumenthal E, Bray E, Lyapichev K, Ramos J, Krishnan V, Lai-Hsu C, Park KK, Tsoulfas P, Lee JK (2013) Perivascular fibroblasts form the fibrotic scar after contusive spinal cord injury. J Neurosci 33:13882-13887. CrossRef Medline

Takeshita S, Kikuno R, Tezuka K, Amann E (1993) Osteoblast-specific factor 2: cloning of a putative bone adhesion protein with homology with the insect protein fasciclin I. Biochem J 294:271-278. Medline

Tan CL, Kwok JC, Patani R, Ffrench-Constant C, Chandran S, Fawcett JW (2011) Integrin activation promotes axon growth on inhibitory chondroitin sulfate proteoglycans by enhancing integrin signaling. J Neurosci 31:6289-6295. CrossRef Medline

Tucker BA, Rahimtula M, Mearow KM (2008) Src and FAK are key early signalling intermediates required for neurite growth in NGF-responsive adult DRG neurons. Cell Signal 20:241-257. CrossRef Medline

Zhu S, Barbe MF, Amin N, Rani S, Popoff SN, Safadi FF, Litvin J (2008) Immunolocalization of Periostin-like factor and Periostin during embryogenesis. J Histochem Cytochem 56:329-345. CrossRef Medline

Zhu S, Barbe MF, Liu C, Hadjiargyrou M, Popoff SN, Rani S, Safadi FF, Litvin J (2009) Periostin-like-factor in osteogenesis. J Cell Physiol 218:584592. CrossRef Medline 